Original article

\title{
Cognitive impairment in the first year after breast cancer diagnosis: A prospective cohort study
}

\author{
Mariana Ramalho ${ }^{\text {a }}$, Filipa Fontes ${ }^{\text {b }}$, Luís Ruano ${ }^{\text {b, c }}$, Susana Pereira b, d , Nuno Lunet ${ }^{\text {b, c, * }}$ \\ a Instituto de Saúde Pública da Universidade do Porto, Rua das Taipas, nº135, 4050-600, Porto, Portugal \\ ${ }^{\mathrm{b}}$ ISPUP - EPIUnit, Universidade do Porto, Rua das Taipas, $n^{\circ} 135,4050-600$, Porto, Portugal \\ ${ }^{c}$ Departamento de Ciências da Saúde Pública e Forenses e Educação Médica, Faculdade de Medicina, Universidade do Porto, Al. Prof. Hernâni Monteiro, \\ 4200-319, Porto, Portugal \\ d Instituto Português de Oncologia do Porto, Rua Dr. António Bernardino de Almeida, 4200-075, Porto, Portugal
}

\section{A R T I C L E I N F O}

\section{Article history:}

Received 15 December 2016

Received in revised form

27 January 2017

Accepted 28 January 2017

Available online 14 February 2017

\section{Keywords:}

Antineoplastic protocols

Anxiety

Breast cancer

Cognition disorders

\begin{abstract}
A B S T R A C T
Objectives: The objective of this study was to assess the relation between cancer treatments and incident cognitive impairment in breast cancer patients, taking into account the levels of anxiety before treatment.

Materials and methods: We conducted a prospective cohort study with 418 newly diagnosed breast cancer patients with no cognitive impairment, defined as values at least 1.5 standard deviations below age- and education-adjusted cut-offs in the Montreal Cognitive Assessment (MoCA), at baseline. The Hospital Anxiety and Depression Scale and MoCA were used for evaluations before treatment and at 1year after diagnosis. We used Poisson regressions to compute adjusted relative risks (RR) and corresponding $95 \%$ confidence intervals $(95 \% \mathrm{CI})$ to identify predictors of cognitive impairment.

Results: The median (Percentile 25, Percentile 75) MoCA score before treatment was 24 (21, 26). A total of 8.1\% (95\%CI: $5.8,11.2)$ of the patients presented incident cognitive impairment during the follow-up. There was a statistically significant interaction between anxiety at baseline and the effect of chemotherapy on the incidence of cognitive impairment ( $P$ for interaction $=0.028$ ). There was a significantly increased risk of incident cognitive impairment among patients with no anxiety prior to treatment with schemes including doxorubicin and cyclophosphamide (adjusted RR $=4.22,95 \% \mathrm{CI}: 1.22,14.65$ ).

Conclusion: There was a statistically significant association between chemotherapy and cognitive impairment, but only among women with no anxiety at baseline.
\end{abstract}

(c) 2017 Elsevier Ltd. All rights reserved.

\section{Introduction}

Worldwide, breast cancer is the leading cause of malignant neoplasms among women, with an estimated 1.67 million new cases in 2012 [1]. Due to improved access to early diagnosis and effective treatments [2,3], breast cancer survival increased over the past years, with the most recent 5-year relative survival estimates surpassing $80 \%$ in several developed countries [4]. The growing number of women surviving breast cancer for longer periods highlights the need for a comprehensive assessment of the burden related to cancer treatment, especially regarding conditions that

\footnotetext{
* Corresponding author. Departamento de Ciências da Saúde Pública e Forenses e Educação Médica, Faculdade de Medicina, Universidade do Porto, Al. Prof. Hernâni Monteiro, 4200-319, Porto, Portugal.

E-mail address: nlunet@med.up.pt (N. Lunet).
}

may be associated with some degree of incapacity throughout life.

Breast cancer and its treatment may be accompanied by several neurological complications [5], which may affect the patients' capacity to accomplish their daily life activities [6]. Although cognitive impairment has been documented among breast cancer patients, its aetiology and determinants remain unclear. Chemotherapy has been the treatment more consistently associated with cognitive impairment among breast cancer patients [7-10], and the pattern of cognitive dysfunction associated with it was named "chemobrain" [11]. However, heterogeneous results across studies may reflect, to some extent, methodological differences, namely regarding the definition of the outcome, the characterization of the exposure and the control of confounding factors [12,13].

In addition to chemotherapy, many other treatments and conditions have been postulated to be related to cognitive impairment, namely radiotherapy [14,15], endocrine therapy [16,17], para- 
neoplastic syndromes [18], increased levels of pro-inflammatory cytokines, especially interleukin 1 and 6 , and tumour necrosis factor [19] and also anxiety and depression [10]; however, findings are inconsistent.

Although anxiety has not been consistently proven to be a risk factor for cognitive impairment [10,20,21], cognitive interference theories suggest that high levels of anxiety are associated with poorer performance in cognitive tests, due to decreasing attentional control $[22,23]$. Therefore, we hypothesized that anxiety prior to treatment may influence the estimated role of potential risk factors for cognitive impairment; this may also contribute to inconsistent findings across studies, and should be taken into account in the interpretation of results. We aimed to quantify the association between cancer treatments and incident cognitive impairment, in early stage breast cancer patients during the first year of follow-up, taking into account the levels of anxiety before treatment.

\section{Methods}

We conducted a prospective cohort study of women with newly diagnosed breast cancer, followed for 1-year, as previously described in detail [24].

\subsection{Assembling of the cohort}

Participants were consecutively recruited in 2012, among women aged 18 years or older, admitted to the Breast Clinic of the Portuguese Institute of Oncology of Porto (IPO-Porto), Portugal, with a potential diagnosis of breast cancer $(N=961)$. We considered eligible those who were proposed for surgery, with histologically confirmed breast cancer diagnosed in the previous three months, not treated with chemotherapy and/or radiotherapy in the chest or axillary areas for other primary cancers, and capable of understanding the purpose of the study $(N=588)$. We excluded those who refused to participate $(N=2)$, those with a Montreal Cognitive Assessment (MoCA) score at least 1.5 standard deviations below age- and education-adjusted cut-offs for possible cognitive impairment at baseline [25] $(N=165)$, and those with stage IV cancer $(N=2)$. We further excluded one woman with missing data on anxiety at baseline. Data from 418 participants was therefore available for the present analysis.

\subsection{Data collection}

Sociodemographic data was collected at baseline, using a structured questionnaire. Information on breast cancer stage and treatment were collected from clinical records.

The Hospital Anxiety and Depression Scale (HADS) [26,27] was used to characterize anxiety and depression at baseline and at 1year of follow-up; scores range from 0 to 21 , and scores greater than or equal to 11 in the respective subscales were considered indicative of clinically significant anxiety and/or depression, as applicable.

The MoCA test was used to evaluate cognitive performance, at baseline and at the 1-year follow-up evaluation. Incident cognitive impairment was considered to have occurred during the first year after the initial assessment when the patient's MoCA score (ranging from 0 to 30) decreased to values at least 1.5 standard deviations below age- and education-adjusted cut-offs for possible cognitive impairment [25].

\subsection{Statistical analysis}

Sample characteristics are presented as counts and proportions for categorical variables, and median and percentiles 25 and 75 (P25, P75) for quantitative variables, taking into account the asymmetry of the corresponding distributions.

We computed cumulative incidence estimates, and the corresponding $95 \%$ confidence intervals $(95 \% \mathrm{CI})$, for cognitive impairment at the 1-year follow-up. Adjusted relative risks (RR) and

Table 1

Sociodemographic and clinical characteristics of breast cancer patients with normal cognitive function for their age and education at baseline $(N=418)$

\begin{tabular}{|c|c|}
\hline & $N(\%)$ \\
\hline \multicolumn{2}{|l|}{ Age $^{\mathrm{a}}$, years } \\
\hline$\leq 55$ & $200(47.8)$ \\
\hline$>55$ & $218(52.2)$ \\
\hline \multicolumn{2}{|l|}{ Education $^{\mathrm{b}}$, years } \\
\hline$\leq 4$ & $198(47.4)$ \\
\hline $5-9$ & $110(26.3)$ \\
\hline$\geq 10$ & $110(26.3)$ \\
\hline Anxiety $^{\mathrm{C}}$ & $159(38.0)$ \\
\hline Depression $^{\mathrm{d}}$ & $34(8.1)$ \\
\hline \multicolumn{2}{|l|}{ Cancer stage } \\
\hline 0 & $29(6.9)$ \\
\hline I & $197(47.1)$ \\
\hline II & $132(31.6)$ \\
\hline III & $60(14.4)$ \\
\hline \multicolumn{2}{|l|}{ Breast surgery ${ }^{\mathrm{e}}$} \\
\hline Breast-conserving & $212(50.7)$ \\
\hline Mastectomy & $206(49.3)$ \\
\hline \multicolumn{2}{|l|}{ Axillary surgery $^{\mathrm{f}}[N=404]$} \\
\hline SLNB & $265(65.6)$ \\
\hline ALND & $139(34.4)$ \\
\hline Chemotherapy & $242(57.9)$ \\
\hline \multicolumn{2}{|l|}{ Timing } \\
\hline Neoadjuvant & $25(10.3)$ \\
\hline Adjuvant & $217(89.7)$ \\
\hline \multicolumn{2}{|l|}{ Schemes } \\
\hline Doxorubicin + cyclophosphamide ${ }^{g}$ & $50(20.7)$ \\
\hline 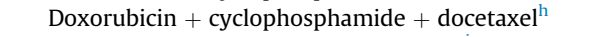 & $24(9.9)$ \\
\hline 5-FU + epirubicin + cyclophosphamide ${ }^{\mathrm{i}}$ & $20(8.3)$ \\
\hline 5-FU + epirubicin + cyclophosphamide + docetaxel $^{j}$ & $144(59.5)$ \\
\hline Others $^{\mathrm{k}} \mathrm{r}$ & $4(1.6)$ \\
\hline Radiotherapy & $303(72.5)$ \\
\hline Brachytherapy & $82(19.6)$ \\
\hline Endocrine therapy & $351(84.0)$ \\
\hline Immunotherapy & $55(13.2)$ \\
\hline
\end{tabular}

ALND, Axillary lymph node dissection; SLNB, Sentinel lymph node biopsy; 5-FU, 5Fluorouracil.

a Range: $27-87$ years.

b Range: $2-22$ years.

Defined as a score $\geq 11$ in the anxiety subscale of the Hospital Anxiety and Depression Scale. The median (Percentile 25, Percentile 75) of the whole sample was $9(6,12)$.

d Defined as a score $\geq 11$ in the depression subscale of the Hospital Anxiety and Depression Scale. The median (Percentile 25, Percentile 75) of the whole sample was $5(2,8)$. Within the group of patients with depression, four patients did not present anxiety $(11.8 \%)$ but the remaining 30 cases reached a clinically significant score in the anxiety subscale ( $88.2 \%$ ).

e Patients who had both breast-conserving surgery and mastectomy are reported as mastectomy.

${ }^{f}$ Patients who had both SLNB and ALND are reported as ALND; does not sum $100.0 \%$ because 14 patients only performed breast surgery.

$\mathrm{g}$ Four cycles of concomitant doxorubicin $\left(60 \mathrm{mg} / \mathrm{m}^{2}\right)$ and cyclophosphamide $\left(600 \mathrm{mg} / \mathrm{m}^{2}\right)$

${ }^{\mathrm{h}}$ Four cycles of concomitant doxorubicin $\left(60 \mathrm{mg} / \mathrm{m}^{2}\right)$ and cyclophosphamide $\left(600 \mathrm{mg} / \mathrm{m}^{2}\right)$, followed by four cycles of docetaxel $\left(100 \mathrm{mg} / \mathrm{m}^{2}\right)$.

${ }^{i}$ Six cycles of concomitant $5-F U\left(500 \mathrm{mg} / \mathrm{m}^{2}\right)$, epirubicin $\left(100 \mathrm{mg} / \mathrm{m}^{2}\right)$, and cyclophosphamide $\left(500 \mathrm{mg} / \mathrm{m}^{2}\right)$.

j Three cycles of concomitant 5-FU $\left(500 \mathrm{mg} / \mathrm{m}^{2}\right)$, epirubicin $\left(100 \mathrm{mg} / \mathrm{m}^{2}\right)$ and cyclophosphamide $\left(500 \mathrm{mg} / \mathrm{m}^{2}\right)$, followed by three cycles of docetaxel $\left(100 \mathrm{mg} / \mathrm{m}^{2}\right)$.

${ }^{\mathrm{k}}$ Four cycles of concomitant doxorubicin $\left(60 \mathrm{mg} / \mathrm{m}^{2}\right)$ and cyclophosphamide $\left(600 \mathrm{mg} / \mathrm{m}^{2}\right)$, followed by four cycles of Paclitaxel $\left(80 \mathrm{mg} / \mathrm{m}^{2}\right)(N=1)$, Four cycles of concomitant cyclophosphamide $(600 \mathrm{mg} / \mathrm{m} 2)$ and docetaxel $\left(75 \mathrm{mg} / \mathrm{m}^{2}\right)(N=1)$, Six cycles of concomitant docetaxel $\left(75 \mathrm{mg} / \mathrm{m}^{2}\right)$ and carboplatin $\left(212 \mathrm{mg} / \mathrm{m}^{2}\right)(N=1)$ and Six cycles of concomitant 5-FU $\left(600 \mathrm{mg} / \mathrm{m}^{2}\right)$, cyclophosphamide $\left(600 \mathrm{mg} / \mathrm{m}^{2}\right)$ and methotrexate $\left(40 \mathrm{mg} / \mathrm{m}^{2}\right)(N=1)$. 
corresponding $95 \% \mathrm{CI}$ for the relation between different characteristics of the patients and the occurrence of cognitive impairment were computed using Poisson regressions. The potential interaction between anxiety status at baseline and the remaining exposures was assessed through stratified analyses by including an interaction term in the regression models. The variables included in each model are described in the footnotes of each table with these results; these correspond to those known to be associated with the exposure and outcome of interest, without being an intermediate step in this relation, as supported by scientific literature.

Statistical analyses were conducted using STATA ${ }^{\circledR}$, version 11.2 (StataCorp, College Station, TX, USA).

\subsection{Ethical approval}

The study was approved by the Ethics Committee of the IPOPorto (CES 406/011) and by the Portuguese Data Protection Authority (Ref. 9469/2012). All participants provided written consent.

\section{Results}

At baseline, $52.2 \%$ of the patients had more than 55 years of age (range: $27-87$ ) and $73.7 \%$ had less than ten years of education (range: $2-22$ ). A total of $54.0 \%$ were diagnosed with breast cancer at stage 0 or I, about half were submitted to mastectomy and just over one-third performed axillary lymph node dissection. Most patients went on to adjuvant treatment, mainly endocrine therapy (84.0\%), radiotherapy (72.5\%) and chemotherapy (51.9\%) (Table 1). All patients completed the 1-year follow-up evaluation; the median (P25, P75) follow-up time was 371 (362-385) days.

\subsection{Anxiety and depression}

At baseline, the median scores in the HADS anxiety and depression subscales were 9 and 5, respectively, corresponding to proportions of patients scoring $\geq 11$ of $38.0 \%$ and $8.1 \%$, respectively.

At the 1-year follow-up, the median scores in the HADS anxiety and depression subscales were 7 and 5, respectively. The corresponding proportions of patients who scored $\geq 11$ were $24.6 \%$ and $13.6 \%$, respectively.

\subsection{Incidence of cognitive impairment}

The median (P25, P75) MoCA score before treatment was 24 (21, 26 ), and during the first year of follow-up, 34 patients presented incident cognitive impairment $(8.1 \%, 95 \% \mathrm{CI}: 5.8,11.2)$. Among those without anxiety at baseline, the median (P25, P75) MoCA score before treatment was $24(22,27)$ and the median $(\mathrm{P} 25, \mathrm{P} 75)$ variation in cognitive performance during the follow-up was $1(-1,2)$. Among those with anxiety, the median (P25, P75) was $24(20,26)$ for the MoCA score at baseline and $0(-1,2)$ for the overall variation.

\subsection{Predictors of cognitive impairment during the first year of follow-up}

Table 2 presents adjusted RR and the corresponding 95\%CI for the relation between different sociodemographic and clinical characteristics of the patients and cognitive impairment during the first year after enrolment, overall and according to the levels of anxiety at baseline. There were no statistically significant differences according to any of the variables considered, when the whole sample was considered. The presence of anxiety at baseline was not significantly associated with cognitive impairment $(R R=1.4395 \%$ CI: $0.73,2.81)$, but the effect of chemotherapy on cognitive impairment was different according to the anxiety levels at baseline; the RR for chemotherapy was 2.81 among patients with no anxiety prior to treatment and 0.50 among those with anxiety ( $\mathrm{P}$ for interaction $=0.028$ ).

Since a statistically significant interaction was observed only for chemotherapy, and an increased risk of cognitive impairment, though not statistically significant, was observed for patients with no anxiety at baseline, we analysed the relationship between different chemotherapy schemes and the occurrence of cognitive impairment among patients without anxiety at baseline, as detailed in Table 3. There was no significant difference in the risk of cognitive impairment according to the timing of chemotherapy, especially when RR estimates were further adjusted to the therapeutic schemes used $(\mathrm{RR}=1.3695 \% \mathrm{CI}$ : $0.10,17.88$ for patients submitted to neoadjuvant and $\mathrm{RR}=1.6595 \% \mathrm{CI}$ : $0.39,6.95$ for adjuvant chemotherapy). Concerning the different regimens of chemotherapy used, women treated with doxorubicin + cyclophosphamide (with or without docetaxel) had a four-fold higher risk of developing cognitive impairment than those not treated with chemotherapy.

\section{Discussion}

Anxiety is one of the most common psychiatric disorders among breast cancer patients [28]. In our study, $38 \%$ of the women were classified as having clinically significant anxiety at baseline, which is a prevalence higher than those found in the general female population [29] and in other studies with breast cancer patients [30,31]. Thompson et al., reported a prevalence of $15.2 \%$ in patients evaluated at least two years after diagnosis [31] and in another study, Hodgkinson et al., found a prevalence of $9.4 \%$ in women evaluated between two and 10 years after cancer diagnosis [30], both using the HADS anxiety subscale and the same cut-off that we used to define anxiety. The different moments of assessment precludes direct comparisons with our results, namely because a decrease in the scores of anxiety in the two years following breast cancer diagnosis has been previously reported [32].

Incident cognitive impairment after one year was observed in $8.1 \%$ of the patients, which is lower than in previous prospective studies evaluating breast cancer patients (range: 15\%-80\%) [7-10]. The variability in results could be explained by the fact that these studies did not use normative data to define the outcome, had distinct definitions of cognitive impairment or had different followup periods. Methodological features such as the patients not being evaluated prior to treatment, and the effect of other medical and psychological conditions, symptoms of distress such as fatigue, or anxiety and also pain further contribute to heterogeneous results regarding the relation between chemotherapy and cognitive impairment [12,13,33,34].

Anxiety has been studied as a possible predictor of cognitive dysfunction $[20,21]$, and its interference with performance in cognitive tests through declining attentional control has been established [22,23], particularly in those abilities that require a high degree of concentration and attention, such as executive and memory function [35-37]. Therefore, cognitive deficits should be interpreted cautiously in the presence of depressive or anxiety symptoms $[38,39]$. In our study, we did not find a statistically significant association between the presence of anxiety at baseline and incident cognitive impairment but our results demonstrated that the effect of chemotherapy on cognitive impairment was different according to the anxiety levels of patients at baseline, in accordance with our initial hypothesis that anxiety prior to treatment may influence the role of potential risk factors for cognitive impairment. It is unlikely that this resulted from the variation of 
Table 2

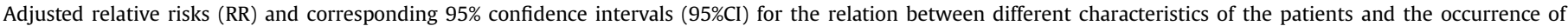
cognitive impairment ${ }^{\mathrm{a}}$ during the first year after enrolment, according to the patients anxiety status at baseline $(N=418)$.

\begin{tabular}{|c|c|c|c|c|c|}
\hline & \multicolumn{2}{|l|}{ All patients $(N=418)$} & \multicolumn{2}{|l|}{ Anxiety at baseline } & \multirow[t]{3}{*}{$P$ for interaction } \\
\hline & & & \multirow{2}{*}{$\frac{\text { No }(N=259)}{\text { Adjusted RR }(95 \% \mathrm{CI})}$} & \multirow{2}{*}{$\frac{\text { Yes }(N=159)}{\text { Adjusted RR }(95 \% \mathrm{CI})}$} & \\
\hline & $\begin{array}{l}\text { Patients with cognitive } \\
\text { impairment }[N(\%)]\end{array}$ & Adjusted RR (95\%CI) & & & \\
\hline \multicolumn{6}{|l|}{ Anxiety at baseline ${ }^{b}$} \\
\hline No & $18(7.0)$ & 1 (ref.) & & & \\
\hline Yes & $16(10.1)$ & $1.43(0.73,2.81)^{\mathrm{f}}$ & & & \\
\hline \multicolumn{6}{|l|}{ Age (years) } \\
\hline$\leq 55$ & $18(9.0)$ & 1 (ref.) & 1 (ref.) & 1 (ref.) & \\
\hline$>55$ & $16(7.3)$ & $0.82(0.42,1.60)$ & $1.10(0.43,2.78)$ & $0.59(0.22,1.63)$ & 0.380 \\
\hline \multicolumn{6}{|l|}{ Education (years) } \\
\hline$\leq 4$ & $15(7.6)$ & 1 (ref.) & 1 (ref.) & 1 (ref.) & \\
\hline$\overline{5}-9$ & $10(9.1)$ & $1.11(0.47,2.63)^{\mathrm{d}}$ & $1.29(0.38,4.36)^{\mathrm{d}}$ & $1.03(0.31,3.45)^{d}$ & \\
\hline$\geq 10$ & $9(8.2)$ & $1.00(0.41,2.42)^{d}$ & $1.62(0.49,5.32)^{d}$ & $0.62(0.16,2.46)^{d}$ & 0.697 \\
\hline \multicolumn{6}{|l|}{ Cancer stage } \\
\hline $0 / \mathrm{I}$ & $21(9.3)$ & 1 (ref.) & 1 (ref.) & 1 (ref.) & \\
\hline II/III & $13(6.8)$ & $0.69(0.34,1.40)^{\mathrm{e}}$ & $1.15(0.45,2.94)^{\mathrm{e}}$ & $0.35(0.11,1.09)^{\mathrm{e}}$ & 0.156 \\
\hline \multicolumn{6}{|l|}{ Surgery $^{\mathrm{C}}\left[N=404^{\mathrm{h}}\right]$} \\
\hline Breast conserving + SLNB & $17(10.8)$ & 1 (ref.) & 1 (ref.) & 1 (ref.) & \\
\hline Breast conserving + ALND & $3(7.3)$ & $0.82(0.19,3.60)^{\mathrm{f}}$ & $0.69(0.07,6.69)^{\mathrm{f}}$ & $1.30(0.11,15.28)^{\mathrm{f}}$ & \\
\hline Mastectomy + SLNB & $6(5.6)$ & $0.54(0.21,1.40)^{\mathrm{f}}$ & $1.19(0.35,4.02)^{f}$ & $0.15(0.02,1.18)^{f}$ & \\
\hline Mastectomy + ALND & $7(7.1)$ & $0.81(0.24,2.66)^{\mathrm{f}}$ & $1.24(0.28,5.52)^{\mathrm{f}}$ & $0.64(0.08,5.00)^{f}$ & 0.180 \\
\hline \multicolumn{6}{|l|}{ Chemotherapy } \\
\hline No & $14(8.0)$ & 1 (ref.) & 1 (ref.) & 1 (ref.) & \\
\hline Yes & $20(8.3)$ & $1.23(0.56,2.71)^{f}$ & $2.81(0.84,9.44)^{\mathrm{f}}$ & $0.50(0.13,1.60)^{\mathrm{f}}$ & 0.028 \\
\hline \multicolumn{6}{|l|}{ Radiotherapy $\left[N=404^{\mathrm{h}}\right]$} \\
\hline No & $9(8.0)$ & 1 (ref.) & 1 (ref.) & 1 (ref.) & \\
\hline Yes & $24(8.2)$ & $0.43(0.13,1.41)^{g}$ & $0.57(0.11,3.06)^{g}$ & $0.48(0.09,2.74)^{g}$ & 0.194 \\
\hline \multicolumn{6}{|l|}{ Brachytherapy $\left[N=404^{\mathrm{h}}\right]$} \\
\hline No & $24(7.3)$ & 1 (ref.) & 1 (ref.) & 1 (ref.) & \\
\hline Yes & $9(11.8)$ & $1.28(0.53,3.12)^{g}$ & $0.64(0.12,3.30)^{g}$ & $1.54(0.49,4.82)^{g}$ & 0.051 \\
\hline \multicolumn{6}{|l|}{ Endocrine therapy } \\
\hline No & $7(10.4)$ & 1 (ref.) & 1 (ref.) & 1 (ref.) & \\
\hline Yes & $27(7.7)$ & $0.76(0.33,1.74)^{\mathrm{f}}$ & $0.41(0.15,1.10)^{\mathrm{f}}$ & $3.08(0.40,23.68)^{f}$ & 0.124 \\
\hline \multicolumn{6}{|l|}{ Immunotherapy } \\
\hline No & $31(8.5)$ & 1 (ref.) & 1 (ref.) & 1 (ref.) & \\
\hline Yes & $3(5.4)$ & $0.66(0.20,2.16)^{f}$ & $0.70(0.16,3.08)^{\mathrm{f}}$ & $0.51(0.07,3.97)^{f}$ & 0.787 \\
\hline
\end{tabular}

ALND, Axillary lymph node dissection; SLNB, Sentinel lymph node biopsy.

a We consider cognitive impairment the decrease from normal values at baseline to abnormal values at 1-year follow-up evaluation.

b Defined as a score $\geq 11$ in the anxiety subscale of the Hospital Anxiety and Depression Scale.

c Patients who had both mastectomy and breast-conserving surgery are reported as mastectomy and those who had both ALND and SLNB are reported as ALND.

d Adjusted for age.

e Adjusted for age and education.

f Adjusted for age, education and cancer stage.

g Adjusted for age, education, cancer stage and surgery.

${ }^{\text {h }} N<418$ because 14 patients only performed breast surgery.

Table 3

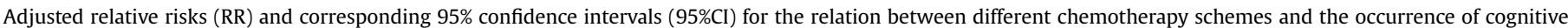
impairment ${ }^{\mathrm{a}}$ during the first year after enrolment in patients without anxiety at baseline $(N=259)$.

\begin{tabular}{|c|c|c|}
\hline & Patients with cognitive impairment $[N(\%)]$ & Adjusted $\mathrm{RR}^{\mathrm{d}}(95 \% \mathrm{CI})$ \\
\hline \multicolumn{3}{|l|}{ Timing of chemotherapy } \\
\hline No chemotherapy & $4(3.7)$ & 1 (ref.) \\
\hline Neoadjuvant ${ }^{\mathrm{b}}$ & $2(13.3)$ & $5.52(0.79,38.77)$ \\
\hline Adjuvant ${ }^{c}$ & $12(8.8)$ & $2.74(0.81,9.57)$ \\
\hline \multicolumn{3}{|l|}{ Chemotherapeutic regimen $[N=257]$} \\
\hline No chemotherapy & $4(3.7)$ & 1 (ref.) \\
\hline Doxorubicin + cyclophosphamide (with or without docetaxel) & $8(15.4)$ & $4.22(1.22,14.65)$ \\
\hline 5-FU + epirubicin + cyclophosphamide (with or without docetaxel) & $6(6.1)$ & $1.59(0.38,6.56)$ \\
\hline \multicolumn{3}{|l|}{ Docetaxel-based chemotherapy $[N=257]$} \\
\hline No chemotherapy & $4(3.7)$ & 1 (ref.) \\
\hline Without docetaxel & $6(12.8)$ & $3.47(0.96,12.56)$ \\
\hline With docetaxel & $8(7.8)$ & $2.17(0.54,8.77)$ \\
\hline
\end{tabular}

a We consider cognitive impairment the decrease from normal values at baseline to abnormal values at 1-year follow-up evaluation.

b Four cycles of concomitant doxorubicin $\left(60 \mathrm{mg} / \mathrm{m}^{2}\right)$ and cyclophosphamide $\left(600 \mathrm{mg} / \mathrm{m}^{2}\right)$, followed by four cycles of docetaxel $\left(100 \mathrm{mg} / \mathrm{m}^{2}\right)$ or six cycles of concomitant docetaxel $\left(75 \mathrm{mg} / \mathrm{m}^{2}\right)$ and carboplatin $\left(212 \mathrm{mg} / \mathrm{m}^{2}\right)$.

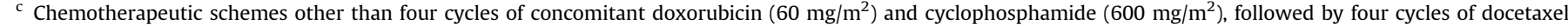
$\left(100 \mathrm{mg} / \mathrm{m}^{2}\right)$ or six cycles of concomitant docetaxel $\left(75 \mathrm{mg} / \mathrm{m}^{2}\right)$ and carboplatin $\left(212 \mathrm{mg} / \mathrm{m}^{2}\right)$.

d Adjusted for age, education and cancer stage. 
anxiety levels during follow-up instead of the baseline levels of anxiety, as the HADS score improved between baseline and the 1year follow-up.

Depression has also been associated with cognitive dysfunction $[10,16,40]$. In our study, the low number of patients with depression that did not present anxiety (only four) limits the assessment of the independent role of depression in the occurrence of cognitive impairment. Similarly, only 30 patients had both anxiety and depression, and therefore our findings related with the effect of anxiety can hardly be explained by the coexistence of these conditions. In a sensitivity analysis excluding the patients with both depression and anxiety (data not shown), our results remained essentially unchanged.

Although an increased risk of cognitive impairment was observed for different treatment modalities and schemes, the strongest association was observed for treatment including doxorubicin and cyclophosphamide, regardless of the use of taxanes. Nevertheless, the fact that all of the patients underwent chemotherapy schemes including more than one agent, limits the assessment of the relative contribution of each agent to the occurrence of cognitive impairment. Previous studies assessing the effect of chemotherapeutic schemes with anthracyclines on cognitive function in breast cancer patients reported inconsistent results $[41,42]$. In a recent prospective study, Van Dyk et al. found no difference in neuropsychological performance during a mean period of five years after treatment when those submitted to anthracyclines were compared to those submitted to nonanthracycline-based chemotherapy [41]. On the contrary, in a cross-sectional study, Kesler et al. reported lower memory scores on average two years after anthracycline treatment when compared to those who underwent other schemes or not submitted to chemotherapy [42]. The former study did not specify the anthracycline used and in the latter, all of the patients performed doxorubicin, which adds to differences in the study design and strategies of data analysis, precluding direct comparisons with our results. Also, the lack of sufficient comparative data makes assessment of the relative contribution of each agent almost impossible and we cannot exclude the possibility that these observed results were found by chance.

The major methodological strengths of our study are the prospective design, with an evaluation of patients before any treatment and after one year, and a complete follow-up. This study design allowed for the use of the 1.5 standard deviations cut-off to define cognitive impairment instead of the more conservative 2.0 standard deviations, as falling below the cut-off represents a decline from a previously measured normal cognitive performance. However, some limitations need to be addressed, especially regarding the external validity of the results. Our study evaluated essentially women with early breast cancer, which limits the generalization to patients with more advanced disease; however, it eliminates brain metastatic diseases which are known to compromise cognitive functioning. Learning effects may have contributed to underestimate the incidence of cognitive impairment, which depended on evaluations with the same instrument at different moments.

In conclusion, this study shows that the association between chemotherapy and cognitive impairment was modified by anxiety at baseline. Among women with no anxiety at baseline, the risk of cognitive impairment was four-fold higher among patients undergoing chemotherapy with schemes including doxorubicin and cyclophosphamide.

\section{Conflict of interests}

None.

\section{Acknowledgements}

The work of FF was co-funded by the Foundation for Science and Technology - FCT (Portuguese Ministry of Science, Technology and Higher Education) and the POPH/FSE Program (Ref. SFRH/BD/ 92630/2013). The Unidade de Investigação em Epidemiologia Instituto de Saúde Pública da Universidade do Porto (EPIUnit) was funded by FEDER through the Operational Programme Competititveness and Internationalization and national funding from the FCT (POCI-01-0145-FEDER-006862; Ref. UID/DTP/04750/2013). Data management activities were supported by the Chair on Pain Medicine of the Faculty of Medicine, University of Porto and by the Grünenthal Foundation - Portugal.

\section{References}

[1] Ferlay J, Soerjomataram I, Ervik M, Dikshit R, Eser S, Mathers C, et al. GLOBOCAN 2012 v1.0, cancer incidence and mortality worldwide. IARC CancerBase No. 11. Lyon, France: International Agency for Research on Cancer; 2013. http://globocan.iarc.fr. Accessed January 1, 2016.

[2] Clarke M, Collins R, Darby S, Davies C, Elphinstone P, Evans V et al. Effects of radiotherapy and of differences in the extent of surgery for early breast cancer on local recurrence and 15-year survival: an overview of the randomised trials. Lancet 2005;366:2087-106.

[3] Jatoi I, Miller AB. Why is breast-cancer mortality declining? Lancet Oncol $2003 ; 4: 251-4$

[4] Allemani C, Weir HK, Carreira H, Harewood R, Spika D, Wang XS, et al. Global surveillance of cancer survival 1995-2009: analysis of individual data for 25,676,887 patients from 279 population-based registries in 67 countries (CONCORD-2). Lancet 2015;385:977-1010.

[5] Khasraw M, Posner JB. Neurological complications of systemic cancer. Lancet Neurol 2010:9:1214-27.

[6] Selamat MH, Loh SY, Mackenzie L, Vardy J. Chemobrain experienced by breast cancer survivors: a meta-ethnography study investigating research and care implications. PLoS One 2014:9:e108002.

[7] Hermelink K, Untch M, Lux MP, Kreienberg R, Beck T, Bauerfeind I, et al. Cognitive function during neoadjuvant chemotherapy for breast cancer: results of a prospective, multicenter, longitudinal study. Cancer 2007;109: 1905-13.

[8] Wefel JS, Schagen SB. Chemotherapy-related cognitive dysfunction. Curr Neurol Neurosci Rep 2012;12:267-75.

[9] Jenkins V, Shilling V, Deutsch G, Bloomfield D, Morris R, Allan S, et al. A 3-year prospective study of the effects of adjuvant treatments on cognition in women with early stage breast cancer. Br J Cancer 2006;94:828-34.

[10] Vearncombe KJ, Rolfe M, Wright M, Pachana NA, Andrew B, Beadle G. Predictors of cognitive decline after chemotherapy in breast cancer patients. J Int Neuropsychol Soc 2009;15:951-62.

[11] Wefel JS, Lenzi R, Theriault R, Buzdar AU, Cruickshank S, Meyers CA. 'Chemobrain' in breast carcinoma?: a prologue. Cancer 2004;101:466-75.

[12] Vardy J, Wefel JS, Ahles T, Tannock IF, Schagen SB. Cancer and cancer-therapy related cognitive dysfunction: an international perspective from the Venice cognitive workshop. Ann Oncol 2008;19:623-9.

[13] Wefel JS, Vardy J, Ahles T, Schagen SB. International Cognition and Cancer Task Force recommendations to harmonise studies of cognitive function in patients with cancer. Lancet Oncol 2011;12:703-8.

[14] Shibayama O, Yoshiuchi K, Inagaki M, Matsuoka Y, Yoshikawa E, Sugawara Y et al. Association between adjuvant regional radiotherapy and cognitive function in breast cancer patients treated with conservation therapy. Cancer Med 2014;3:702-9.

[15] Phillips KM, Jim HS, Small BJ, Laronga C, Andrykowski MA, Jacobsen PB. Cognitive functioning after cancer treatment: a 3-year longitudinal comparison of breast cancer survivors treated with chemotherapy or radiation and noncancer controls. Cancer 2012;118:1925-32.

[16] Bender CM, Sereika SM, Berga SL, Vogel VG, Brufsky AM, Paraska KK, et al. Cognitive impairment associated with adjuvant therapy in breast cancer. Psychooncology 2006;15:422-30.

[17] Castellon SA, Ganz PA, Bower JE, Petersen L, Abraham L, Greendale GA. Neurocognitive performance in breast cancer survivors exposed to adjuvant chemotherapy and tamoxifen. J Clin Exp Neuropsychol 2004;26:955-69.

[18] Gultekin SH, Rosenfeld MR, Voltz R, Eichen J, Posner JB, Dalmau J. Paraneoplastic limbic encephalitis: neurological symptoms, immunological findings and tumour association in 50 patients. Brain 2000;123(Pt 7):1481-94.

[19] Reichenberg A, Yirmiya R, Schuld A, Kraus T, Haack M, Morag A, et al. Cytokine-associated emotional and cognitive disturbances in humans. Arch Gen Psychiatry 2001;58:445-52.

[20] Cimprich B, So H, Ronis DL, Trask C. Pre-treatment factors related to cognitive functioning in women newly diagnosed with breast cancer. Psychooncology 2005:14:70-8.

[21] Mandelblatt JS, Stern RA, Luta G, McGuckin M, Clapp JD, Hurria A, et al. Cognitive impairment in older patients with breast cancer before systemic 
178

M. Ramalho et al. / The Breast 32 (2017) 173-178

therapy: is there an interaction between cancer and comorbidity? J Chin Oncol 2014;32:1909-18.

[22] Gas CS, Curiel RE. Test anxiety in relation to measures of cognitive and intellectual functioning. Arch Chin Neuropsychol 2011;26:396-404.

[23] Eysenck MW, Calvo MG. Anxiety and performance: the processing efficiency theory. Coon Emot 1992;6:409-34.

[24] Pereira S, Fontes F, Sonin T, Dias T, Fragoso M, Castro-Lopes J, et al. Neurological complications of breast cancer: study protocol of a prospective cohort study. BMJ Open 2014;4:e006301.

[25] Freitas S, Simoes MR, Alves L, Santana I. Montreal cognitive assessment (MolA): normative study for the portuguese population. J Chin Exp Neuropsychol 2011;33:989-96.

[26] Pais-Ribeiro J, Silva I, Ferreira T, Martins A, Menses R, Baltar M. Validation study of a portuguese version of the hospital anxiety and depression scale. Psychol Health Med 2007;12(225-35):35-7.

[27] Zigmond AS, Snath RP. The hospital anxiety and depression scale. Acta Prychiatr Sand 1983;67:361-70.

[28] Mass SW, Roorda C, Berendsen AJ, Verhaak PF, de Bock GH. The prevalence of long-term symptoms of depression and anxiety after breast cancer treatment: a systematic review. Maturitas 2015;82:100-8.

[29] Comers JM, Goldener EM, Waraich P, Hst L. Prevalence and incidence studies of anxiety disorders: a systematic review of the literature. Can J Psychiatry 2006;51:100-13.

[30] Hodgkinson K, Butow P, Hunt GE, Pendlebury S, Hobbs KM, Wain G. Breast cancer survivors' supportive care needs 2-10 years after diagnosis. Support Care Cancer 2007; 15:515-23.

[31] Thompson J, Coleman R, Colwell B, Freeman J, Greenfield D, Holmes K, et al. Levels of distress in breast cancer survivors approaching discharge from routine hospital follow-up. Psychooncology 2013;22:1866-71.

[32] Stafford L, Komiti A, Busman C, Judd F, Gibson P, Mann GB, et al. Predictors of depression and anxiety symptom trajectories in the 24 months following diagnosis of breast or gynaecologic cancer. Breast 2016;26:100-5.

[33] Falleti MG, Sanfilippo A, Maruff P, Weih L, Phillips KA. The nature and severity of cognitive impairment associated with adjuvant chemotherapy in women with breast cancer: a meta-analysis of the current literature. Brain Cog 2005;59:60-70.

[34] Minisini A, Atalay G, Bottomley A, Puglisi F, Piccart M, Biganzoli L. What is the effect of systemic anticancer treatment on cognitive function? Lancet Oncol 2004;5:273-82.

[35] Ross SR, Putnam SH, Grass CS, Bailey DE, Adams KM. MMPI-2 indices of prychological disturbance and attention and memory test performance in head injury. Arch Chin Neuropsychol 2003;18:905-6.

[36] Grass CS, Ansley J, Boyette S. Emotional correlates of fluency test and maze performance. J Chin Psychol 1994;50:586-90.

[37] Grass CS. MMPI-2 variables in attention and memory test performance. Psychol Assess 1996;8:135-8.

[38] Groth-Marnat G. Neuropsychological assessment in clinical practice: a guide to test interpretation and integration. New York: John Wiley and Sons Ltd; 2000.

[39] Sweet JJ, Newman P, Bell B. I-IIISignificance of depression in clinical neuropsychological assessment. Chin Psychol Rev 1992;12:21-45.

[40] Stewart A, Collins B, Mackenzie J, Tomiak E, Verma S, Bielajew C. The cognitive effects of adjuvant chemotherapy in early stage breast cancer: a prospective study. Psychooncology 2008;17:122-30.

[41] Van Dyk K, Petersen L, Gan PA. Comparison of neurocognitive function after anthracycline-based chemotherapy vs nonanthracycline-based chemotherapy. JAMA Oncol 2016;2:964-5.

[42] Kesler SR, Blayney DW. Neurotoxic effects of anthracycline- vs nonanthracycline-based chemotherapy on cognition in breast cancer survivars. JAMA Oncol 2016;2:185-92. 